\title{
Growing Up Married (2016): Representing Forced Marriage on Screen
}

Growing Up Married is a 27-minute documentary that focuses on the stories of four child brides from Turkey, recollecting their memories as adults. I started this project with a desire to give voice to women's stories that were discursively silenced, and with the aim of drawing attention to the significance of activism in feminist media research. In this article, I provide a critical reflection on the process of making this documentary while exploring the ways in which women articulate their experiences of being child brides and being forced into marriage. I argue that women speaking out about these experiences not only reveal issues around forced marriage, but, more significantly, shed light on stories of domestic violence, sexual abuse as well as child abuse. They also highlight the ways in which the concept of 'honour' is perceived within the social and cultural contexts of Turkey. Indeed, they reveal clearly the ways in which a cultural obsession with family 'honour' and women's chastity are produced and reinforced. I employ discourse analysis to examine the patterns that emerge within the film's subjects' stories. I also use critical analysis to reflect on the filmmaking process as this offers an exploration of the intractable nature of the topic while revealing the complexities around making feminist media.

According to the UNICEF report Ending Child Marriage: Progress and Prospects (2013), there are 700 million women who were married as children, and 280 million girls are at risk of becoming child brides. According to CARE 'almost 39,000 girls become child brides every single day, often married to much older men' (care.org, 2018). In Turkey, the reports written by the Turkish Population Research (cited in Hurriyet, 2015) reveal that 1 in 3 marriages involves a girl under the age of $18 .{ }^{1}$ The figures here are alarming and signal the need for further and urgent research in the field. I wanted to explore the effects of child and forced marriage while making women's experiences visible and audible, in an attempt to contribute to and advance debates around this significant, complex and

\footnotetext{
${ }^{1}$ The law itself is ambiguous and inconsistent when it comes to identifying what the age of consent is. The Turkish Criminal Code deems it illegal to marry children under 17 (or 16 if they reached puberty). The Turkish Child Protection Law sees the age of consent as 18. The Turkish Civil Code said 15 until recently when it was raised to 18 (with the exception that if the parents give consent then it is 17 or under special circumstances it can be lower than 17).
} 
emotionally charged human rights issue which has often been silenced. Indeed, at the heart of Growing Up Married is the concept of voice.

Existing scholarship in the field of child brides and media is limited. The one article written in Turkey/Turkish, directly related to the link between the media and child marriage (Ova, 2014), argues that media representations of child brides offer a problematic, sensationalist and marginalising discourse while focusing on individualised stories of girls' terrorised lives: 'It is ideological that girls who do not have any say on their life choices are represented in the news as if they are responsible for everything they do as brides... It is through this that a 'guilty child' discourse is legitimised' (Dursun cited in Ova, 2014, 245, my translation). Growing Up Married avoids this problematic sensationalist discourse by employing different approaches to filming and editing and through the method of unstructured interviews. Rather than asking the interviewees structured questions that would lead me to present a particular point, I asked them to tell me about the story of their lives. Some chose to start from their childhood, as disturbed by being forced into marriage; some started with the issue of a violent experience they went through which defined the story of their lives. I provide instances of these later in the article. Worth signalling here is that, although the women in the documentary were not involved in the editing process (a collaborative approach frequently used in progressive feminist practice), they were shown the final product. Responding to seeing herself on screen, one of the participants said she 'wanted to see more of herself' and asked if I would be making 'a longer film'. Another participant spoke of 'the power she felt she was given in this project' and how it helped her come to terms with some of the violent experiences she went through:

I have always had the need to tell someone about what I went through. Eylem made me feel at ease. She is a lovely and kind person. Sharing my story with her was totally comforting. Such a huge relaxation. Years' worth of secrets. I told her everything and it filled me with confidence and I am glad lots of people will hear about it. It doesn't matter who I am, if my story can change one person's idea about forced marriage... then I will be even happier. (Leyla's reflection, 2016, my translation) 
It is important here to disclose my position as a scholar and filmmaker in contextualising the documentary's aims and the rationale behind it. I am a UK-based and trained feminist media scholar. I am originally from Turkey, engaging for the first time, in media production. This positionality is significant because I am not only a woman making media, but an academic woman making media as a method to engage in research questions around violence against women in general, and forced marriage and child brides in particular. The impetus to produce the film came from my academic projects over a number of years exploring gender politics and the Middle East, representations of religion, violence against women (in the form of 'honour' crimes, virginity tests, forced marriage and domestic sexual violence) in the media in general, and in films in particular. Yet, switching from theory to practice presents its own challenges, as one moves from critiquing media to making media. The questions posed shift their focus from how are women represented in this film to how do $I$ represent in my film the, at times, un-representable violence (physical, emotional, verbal) while avoiding 're-victimising' the interviewees (Hlavka, Kruttschnitt and Carbone-Lopez, 2007).

Indeed, as suggested by Leyla's reference to my role in putting her at her ease (the situation described as comforting, relaxing), the relationship between filmmaker and participant is at the root of power relationships and ethical concerns in documentary production and representation. There are, of course, long standing debates within feminist work on the politics of research with and interviewing women particularly in terms of power and voice. Feminist scholarship has explored the range of social attributes - including class, race, ethnicity and educational capital - that can shape the balance of power within the interview encounter (Fonow and Cook, 1991 and 2011; Riach, 2009; Ribbens, 1989; Maynard and Purvis, 1994; Hlavka, Kruttschnitt and Carbone-Lopez, 2007; DeShong, 2013;Tang, 2002). As Sharlene Nagy Hesse-Biber aptly points out, 'Feminists doing international research, who attempt to speak for "the other/s" in a global context, should be particularly mindful of the inherent power dynamics in doing so,' and call for a heightened attention to power and difference' $(2012,14)$. My analysis of Growing Up Married here, in which I critically reflect on these power relations, is an attempt to frame these debates in relation to the political aspects of the documentary, that is, the desire 
to let marginalised voices come through and be heard. Indeed, the concept of voice, which is at the heart of this project, has been discussed from different perspectives in relation to documentary practices. As Kim Munro reminds us, it might refer to the 'voice of documentary' (the term coined by Bill Nichols as cited in Munro, 2018, 70) or may be approached in regard to its 'social function in enabling the previously unrepresented a measure of agency' (ibid., p.70). In documentary film, she goes on to point out, voice can also refer to modes of address in narration or how interviews are used. Who speaks, who is spoken of and how the speaking occurs, as Munro aptly puts it, reveals issues around representation, identity and power (ibid. p.70). The existing literature on feminist research is mainly focused on the potential disempowerment of the researched and the inequalities between the researcher and the researched. Anne Opie's critique of positioning women in the research process as 'being guided to consciousness' while the researcher 'is consistently privileged' poses a significant issue highlighted in Ning Tang's article, on interviewer and interviewee relationships between women: 'Is this empowerment of the researched or empowerment of what the researcher wants?' (Opie cited in Tang, 2002, p. 706). By contrast, during the interviews I was very much overwhelmed by the power of the experiences of women that this notion of the subjects of research having less power was completely destroyed. This was replaced by my thoughts of being challenged and disrupted as the researcher.

Diane Waldman and Janet Walker refer to Calvin Pryluck's 1976 article on the ethics of documentary filming, entitled, thought-provokingly, 'Ultimately We Are All Outsiders'. Here, he refers to the power imbalance between the filmmakers and subjects as endemic, while reminding practitioners and other readers that 'we can take our gear and go home' while they have to continue their lives where they are (Pryluck cited in Waldman and Walker, 1999). Acknowledging the moral and ethical dilemmas and responsibilities of the act of filming is crucial. This is the reason why I still remain in touch with two of the four women interviewed for the film ${ }^{2}$, and let them know how each screening went and what comments were received. Indeed, the film had an impact on its participants. For

\footnotetext{
${ }^{2}$ I have not been in touch with the other two women, who I met at the Women's Support Centre. They were sent the link to the documentary, but have not communicated with me since.
} 
example, one of the women in the documentary (Avniye), for whom it was the first time speaking about her story out loud, said her life has changed significantly and positively for having spoken to me, for the project. As noted by Hesse-Biber, 'Feminist research practitioners pay attention to reflexivity, a process whereby researchers recognise, examine, and understand how their social background, location, and assumptions affect their research practice' (ibid., 17). My experience of Growing Up Married suggests that this process continues well past the period of production, becoming an evolving relationship between filmmaker and subject. Alexandra Juhasz's (2003) article on feminist collaborative video is pertinent here. Juhasz reflects on the experience of working with women prisoners on a film project and concludes that 'even a fully realized and successful collaboration [between the filmmaker and those filmed] cannot fully undo the divides of difference, position, and victimization that define documentary' (2003, p.76). Juhasz's argument brings to mind the question of why should we bother at all if we cannot divorce ourselves from a web of power relations. However, her argument is essentially linked to the concept of the impact of practice research: 'As a feminist documentarian who has taken others' images to be used in the service of political projects in which we all share, I make it my central concern to consider what social effects come from our work, and at what cost' (ibid., p. 80). Growing Up Married is not an example of collaborative feminist practice per se - although it could be regarded as such had the participants of in the documentary been involved in the editing of their own stories for the final product. My ongoing relationship with the participants and inclusion of their views with respect to dissemination of the film suggests that an argument can be made for inclusion as a counterpoint to collaboration. It also needs to be acknowledged that their act of speaking out about their experiences have so far encouraged disclosures at different screenings. And I see it as my responsibility as the researcher/filmmaker to provide the participants with feedback from different screenings that have been taking place around the world. This signals my commitment to allowing them to see how they have become agents of change for others.

Sandra Harding states that 'Researchers often bring to research situations a higher social status than those they study... In addition to this source of inequality between researcher and researched, the 
structurally designated relation between the researcher and the researched appears to be intrinsically socially unequal, even a "colonial” relation' (2012, p. 52). She goes on to argue that ' $\ldots$ it should be recognised that the social status of the researcher and the researched bring to research process are, for the most part, permanent. 'No amount of empathy, careful listening, or "going native", as valuable as such strategies may be' will erase differences (Harding, 2012, 53). It is unlikely that these differences can be eradicated completely, and they do need to be fully acknowledged, but, I argue that as feminist scholars, we risk imprisoning our work within discussions around differences and inequalities. In other words, while awareness of hierarchies necessarily underpins feminist practice, our work has the power of making a difference by positively impacting policy and society. For this reason, I argue that the dissemination of feminist research has the potential to become a form of feminist activism, which then would allow academic research to travel outside academia. Below, I would like unpack this argument further by providing the case for the impactful dissemination of Growing Up Married.

\section{Dissemination of the documentary as a form of feminist activism}

I am aware that the four women in Growing Up Married are distinct from me, that I hold the power of filming them and editing their stories, and that there is nothing that can undo this inequality. My work arises from informed knowledge of that relationship. However, I also want to argue that dissemination of the documentary has allowed this feminist project to find a way into policy frameworks, raising important questions of women's experience. Indeed, Growing Up Married responds to the needs of policies around forced marriage and violence against women, and demonstrates how significant it is to build bridges between cultures and countries on significant human rights issues. It is important to acknowledge that my film and research come out of a very particular context - the legacy of forced marriage in Turkey. Yet, this is a much wider issue that goes beyond the borders of Turkey. Forced marriage happens in the UK and it happens globally. In this regard, the project also signals how feminist film research is at the forefront of questioning and analysing differences across all borders. Growing Up Married shows the potential of feminist scholarship to forge change and to bring women together across difference. Moreover, the documentary's journey to date shows how stories of women 
in Turkey can be useful in informing policy in the UK around forced marriage. It is thoughtprovoking to see, though without suggesting that women's experiences can be universalised, how experiences of women in Turkey can travel through film to the UK and have an impact on policy and society. Through significant and international levels of media engagement as well as a series of public engagement activities (through screenings and working with local, national and international institutions - from Norfolk Constabulary to the NHS, the Forced Marriage Unit and the House of Lords), the project has been influential in building bridges between cultures and countries on this significant human rights issue. The project enabled Turkish women's stories to influence the way in which policies around forced marriage in the UK are discussed and decided. The documentary was used to affect policy at local and then inform political debates at national level while also raising awareness of the issue at international level with visibility at conferences, international film festivals and through other public and media engagement activities. Since its release, the film has been watched by over 3000 people worldwide (at public screenings, academic conferences and screenings at universities); it was the focus of news items in international media in more than 20 media outlets (including New York Times, Al Jazeera, and Reuters); was discussed at the House of Lords' Women Worldwide Advancing Freedom and Equality Seminar (by invitation of Baroness Gould); has been used by the Norfolk Constabulary in training police officers, NHS professionals, and the Safeguarding Children Unit; and will be screened at Westminster in conjunction with the newly proposed bill on forced marriage. ${ }^{3}$ Since April 2016, I have been a member of the Honour Based Abuse, Female Genital Mutilation and Forced Marriage Partnership Strategy/Policy Group and have been attending meetings and presenting about the film.

The Constabulary's decision in using the documentary in their training brings us to the concept of voice. Forced marriage is an issue that is not voiced much. The Constabulary's decision to use the film in the training of agencies and communities they work with has precisely been for this reason. As Amanda Murr (2017), from Norfolk Constabulary, explained:

\footnotetext{
${ }^{3}$ By Baroness Tonge, the publication/approval date of the bill is not yet confirmed.
} 
Growing Up Married offered an opportunity to remind agencies and the community regarding how we as the Constabulary can implement prevention and disruption options to manage perpetrators of this abuse. This documentary most importantly acts as a platform highlighting the "victims" voice which is at times is silenced due to the abuse they suffer at the hands of their abusers. This is such an important message for our agencies to be aware of. Also, we will use this to get communities to look for community driven solutions to identify that victim suffering abuse, who is silent amongst them who needs help but safely without stigma or shame. ${ }^{4}$

The project has, so far, played a significant role in increasing the confidence of victims, survivors and affected communities to come forward. These activities demonstrate the impact the documentary has had to date at the level of feeding and informing policy development. In addition, it has been fruitful as a public and media engagement project. For me, these activities are very much acts of feminist practice through research. In addition, regarding the production of the documentary, I argue that the mere fact that it was possible to hear the stories of four women is a feminist act itself. I am not suggesting that questions around voice, power and positionality are not significant or that they should not be critically reflected on. However, I do argue that, while there is value in being self-reflexive, the concept of public engagement with research can allow feminist projects to find a way into policy framework and have a positive impact on society. Having provided my approach to the dissemination of the documentary, below, I provide a self-reflexive account of how I gained access to the interviewees, the process of filming and editing and the ethical challenges that these posed. In doing so, I aim to examine the ways in which the four women in the film talk about their experiences of forced marriage and being child brides.

Diana M. Petrarca and Janette M. Hughes' (2014) recent research on mobilising academic research via documentary filmmaking is worth referring to here. They suggest that 'academic research is typically written in a style and for venues that remain largely inaccessible by the general public and

\footnotetext{
${ }^{4}$ Amanda Murr, Safeguarding Development Officer, Norfolk Constabulary, $8^{\text {th }}$ November 2017
} 
even the practitioners who might benefit from it. To make academic research accessible outside academia means, as Corinne Glesne puts it, 'creating [research] in forms that others will want to read, watch, or listen to, feel and learn from the representations' (2010, p. 262). As highlighted by E. Ann Kaplan's reflection: 'Film is an important object for feminist practice, since creating art or entertainment with feminist perspectives may help to change entrenched male stances towards women that can be found in commercial or avant-garde entertainment and art' $(2000$, p. 2). In doing so, feminist film study may change cultural attitudes towards women, and may deepen our understanding of meanings women have traditionally born in patriarchal cultures.

\section{The Filming Process}

In 2015, as I was writing up an article theorising feminism and the representation of 'honour' killings in films from Turkey, I came to realise that what was missing in my work were the voices of women. I was at risk of making generalised assumptions around what womanhood entails within the context of Turkish society. It was at that point that I decided to take on the new challenge of making a film, rather than critiquing films at a theoretical level. With zero budget but a return ticket, I borrowed a camera from the University Television Studio and travelled to Turkey. This move, from theory to practice, originated with a previous conversation I had had with Avniye, one of the interviewees in the film, who is also a neighbour of my parents. In a previous visit to Izmir, the third biggest city, known for being the most 'Westernised', secular and modern in Turkey, Avniye had asked me if I could have a chat with her 16-year-old daughter, who was eager to drop school and get married to the man she was in love with, who was ten years her senior. It was at that point that she started telling me about her life and her story of forced marriage as a child, virginity tests, domestic sexual violence and abuse.

Personal connections and friendships my mother had, led to having access to Leyla and Avniye. Leyla, just like three other women from the neighbourhood, heard that I was making a film about child brides, and knocked on my parents' door at 10.30 at night, to ask if she could talk, too. This was 
a pivotal moment for me to realise what an ordinary yet invisible experience forced marriage and child brides are in Turkey. Women were prepared to speak out and they were clearly looking for ways in which they could act on this desire. The relationship that I had formed previously with these women highlighted the extent to which they positioned me as an insider. If a journalist from the UK decided to make a film and somehow had access to these interviewees, would he/she be welcome to listen to these stories in the same way that I was? Possibly not. Being a woman, younger than the interviewees, and being a native, and having my mother in the room during the interviews were all helpful. In fact, Avniye's interview was the first I filmed, and I asked her to talk to my mother instead of looking at me as I stood behind the camera. This created a space in which she felt comfortable. The experience of filming made me realise how the consent forms I got the interviewees to sign was merely a piece of paper, and the fact that they were speaking about their personal experiences of marriage was a feminist act in itself. They spoke because they wanted to, and in doing so, they have given access to their stories through the film while encouraging other women (who would watch the film) to disclose their stories. This is evident in the disclosures I receive from women who watch the film, after almost every screening.

Half of the filming took place at the Women's Support Centre in Tire, Izmir. Getting access to the Centre would not have been as straightforward had my cousin not been in charge of running the centre. She introduced me to the two women who happened to be visiting the centre the day of the filming and they agreed to tell their stories as long as their faces were not fully shown in the film. These interviews were not arranged for a particular time or date. I told the interviewees about my plan to make a film about child brides and they agreed for their experiences to be recorded on camera as long as my cousin, who knew both of them already, was in the room with them. Audiences tend to ask me if I took a film crew to Turkey to do these interviews. I did not. In all four of the interviews I was behind the camera, asking questions, and I used a camera, a tripod and a voice recorder. It was thought-provoking to question whether these women would speak out in the presence of a crew. The irony was that they were happy for their stories to be used in a film, and they thought, as one of them 
said: 'I don't want other girls to suffer. They should hear me talking and make sure they are educated and they are financially independent. Listen to my story and don't accept to be wed without love.'

The filming at the Centre, because the interviews were ad hoc in nature, was a challenge for someone, like me, who was not used to the practice of filmmaking. It is, in many ways, a different act to sit and watch films and critique them, rather than making them. The challenge was even more complicated: the two women interviewed at the Centre had not informed me about what they were going to tell me about their lives. I did not realise the extent of the violence (in one case this involved two experiences of rape) they were going to share with me. Adding to this was the unstructured nature of the interviews. I did not ask pre-formed questions. Instead, I asked them to speak about their lives for a documentary about child brides and forced marriage.

One of the challenges during the filmmaking process was that there was not an opportunity for a second take. A case in point here is the interview I did with one of the women who was telling me about her experience of rape. It was difficult for her to articulate this anyway, and despite the unwanted background noise during the interview, I was not in a position to ask for a second take. This taught me that filming the experience of violence in 'perfect' conditions, is not possible. There are other ethical issues attached to this. Indeed, there is a body of literature regarding ethical issues surrounding this kind of research and the impact of, as Hlavka et al. put it (2007), 'revictimizing the victims' and interviewing about interpersonal violence. In fact, as discussed in their work (2007), there are studies that indicate that 'women do not disclose their traumatic experiences until they are involved in a research project that seeks information about victimization status or experience' (Smith et. al., 2000 and Ullman, 1996 cited in Hlavka et. al., 2007, 897). I was wary of this and intentionally tried to avoid a discourse of victimisation throughout the filming and editing processes. The aesthetics of the film, then, is very much informed by the content. I regarded it as an ethical duty to keep the interview as 'naturally flowing' as possible. Rather than presenting women's stories as stories of victims, I tried to edit the documentary in ways that would allow the audience to see how strong and powerful these women are for they resisted and fought for their rights. I intentionally focused on the 
emotional and psychological dimensions of the relationships from the women's perspective in an attempt to carry the stories in the most unobtrusive way possible.

There is a challenge in conducting analysis and presenting findings in a way 'that sensitively captures the multiple levels of a research encounter', as Riach also points out in her work about participantcentred reflexivity in the research interview $(2009,356)$. Here, I expand her discussion to challenges in the editing suite, through to the post-production process. In the editing room, from hours of footage, one has to construct a story. There were times when I thought it would have been more ethical to have the women interviewed for the film in the editing room. In fact, I have called and consulted Leyla's and Avniye's opinions on the stories I was constructing from their stories. I also shared some of the footage with them when and where possible. I remember Avniye asking if I could extend her story and tell the audience about how much she loves her 'new' husband. I remember explaining to her that the film's aim was to privilege her own voice and was not to show her life as dependent on one man. Moreover, as I will refer to in the conclusion of this article, Leyla is the one who determined the ending of the film by sending a photo of herself a year after the filming took place. One cannot escape power dynamics but reflexivity can be seen 'as embedded in the moment [filming], as well as after that moment has passed [editing]' (Riach, op. cit., 358).

\section{Discourses of forced marriage}

Violence occurs at different levels: sexual, physical, psychological and verbal. These women's lives are shaped by violence. Although each and every experience I listened to was unique, the way in which the stories were told revealed that they had shared themes and there were patterns in the language each woman used.

'I was 14 when I got married... He was $25 . .$. It was an arranged marriage. I never wanted it but my mum forced me to marry... My dad was a very aggressive man. He used to beat my mum all the time... She wanted me to get married and survive. She forced me to marry the neighbour's relative... The day I married him I hated all men.' 
Even though Leyla never explained in detail as to why this hatred emerged, it becomes clear later on in the interview that she was sexually violated by the man she was forced to marry:

'All I wanted to do was to go out and play hopscotch with my friends. I used to dread nighttimes... He used to drag me to the bedroom and took pleasure out of pulling my hair. I used to collect all my hair from the floor and pillows every morning. Then I started cutting my hair so that he couldn't hurt me as much!'

Women find strategies to cope with sexual abuse. Although they do not refer to sexual violence in their marriage as rape, they articulate how sex was something that was forced on them. Leyla's words reinforce this idea: 'I'd rather get beaten than let him touch me. I would do anything to avoid him kissing me or touching my breasts... I used to run away from the house even in the night. I was scared of falling asleep at night in case he would come near me.' Two of the four women secretly used birth control pills so that they protected themselves from getting pregnant. Leyla's recollection of this is highlighted in her words: 'There wasn't anything wrong with me. He took me to several doctors. I simply didn't tell anyone I was on the pill!' As she says this, she smiles. But, this smile turns into a distressed expression quickly as she remembers her mother's words: 'It's just a five-minute job! Just close your eyes and do it [get pregnant]!' It is after her mother's words that Leyla got pregnant. Leyla, just like the other three women interviewed finds sex 'revolting'.

It is thought-provoking that in all four experiences, the key people who make decisions about their daughters are not men but women - mothers or mothers-in-law. What is even more striking though is that they choose these paths for their daughters to help them 'survive' and so they do not end up suffering in marriages in which they are unhappy and violated. Growing Up Married makes connections between the violence enacted upon women by men, on women by women and that which women enact on themselves. It is a violence which spans generations. 
'I was 14 when I got pregnant with my first child. I miscarried while doing heavy housework. Then got pregnant again. She was 18 days old. I couldn't figure out how to look after it. I woke up one morning and found her dead, lying next to me. 5 of them dead, 2 alive!' says one of the interviewees, who was forced to marry her cousin. Correspondingly, Avniye luridly describes how her daughter was born with a broken arm as a result of the violence she was subjected to while she was pregnant. She articulates boldly how she was breastfeeding her baby after having been brutally beaten by her husband, too. Another interviewee speaks of beating her own son up because he was an unwanted baby resulted from rape in marriage.

Although there are four different women, their stories are almost intertwined into one story. When one of the women talks about how she was repeatedly beaten by her husband who 'tortured' her, she is in fact, reminding us of the same experience Leyla's mother had with her husband who used to beat her for no reason - 'if dinner was not served on time, he would beat her; if she forgot to draw the curtains in the evening, she would get beaten...' The stories complete each other and signal how there are patterns to women's suffering in forced marriage as child brides. Often these 'brides' came from violent and abusive backgrounds. One woman, talks about the effects of two different experiences of rape at the age of 4 - one by a man, the other by her 'own aunt': 'When I told these to my family... they said I was promiscuous at the age of 4! What can a 4-year-old girl know about sex?!' She starts talking about the abuse, then sighs and stops: 'I feel like I'm re-living that moment!' We stopped the interview there and then. It was clear, though, that these experiences resulted in a sexual dysfunction: 'It still has a huge impact on my physical life... I don't take pleasure from sex.'

Avniye's account reveals cultural attitudes towards girls when they reach puberty: 'In our town, when a girl turns 15 or 16 she will be seen as a spinster if she isn't married.' Avniye's story recounts the way in which she was physically taken by her family and paraded in front of people she had never seen before: 'They put a wedding gown on me one night and took me to some place I had never seen before. I was sitting next to my aunt in the car. I asked her: 'Auntie, where am I being taken to?' She 
pinched my arm and said: 'Stop talking! It is rude to talk!' I [have] remained silent since.' Ideas about women's bodies as property also play a key part. Avniye's image while telling her story is juxtaposed with shots of a bride in a white wedding dress to signal the cultural meaning of the wedding dress - associated with the celebration of traditional femininity, it can also be seen as a cage when shown alongside these stories of abuse.

Avniye was 15 when she was forced to marry a man she had never seen before she was left in the same bedroom with him:

'I was left alone with him after everyone disappeared. And then, without a word... I wanted a glass of water... I was shaking. Couldn't even drink it... [she pauses]. The next morning, they wanted to see the sheets. I wasn't prepared for anything. I've no idea how I went through it. So, when what they wanted didn't happen... There was no blood on the sheets as my hymen was elastic. He went outside and said to his family: "You bought me a woman, not a girl!" That marked the beginning of an awful life.'

What she is telling us here is important, but what is more thought-provoking is what she is not able to articulate. Her facial expressions reveal the difficulty she has in expressing the difficult moment she witnessed. The larger families' involvement in marriage is evident in her words and indicate a common practice in Turkey. Families often receive payment (bride price) for their daughters, and it is for this reason that parents actively contribute to these practices. They are present along every step of the way in order to ensure that their daughters carry out their bridal duties, from wedding vows to post-wedding sex.

\section{Conclusion}

In responding to one of feminism's central claims, that women's perspectives have often been silenced or ignored, my research is interested in listening to women's experiences, and making them not only audible but also visible in the form of a film. This, of course, brings up certain questions: 
What does a film allow that, for example, a journal article does not? A research film not only allow us to hear the voices of women but also enables us to directly capture the nuances of gesture, facial expression and vocal intonation and emphasis. This is particularly powerful in the context of sharing the experiences of women and letting the film travel. With this film I wanted to give voice to women's stories that they were otherwise not able to tell. This required a critical reflection on the question of: what is the best medium to give that voice? Had I chosen to record women's voices and used them to quote them in an academic article, would it have the same reach the film already had? In this regard, I am mainly interested in discussing ways in which, as feminist media scholars, we can consolidate feminist research and practice as a method of activism. As Harriet Jacobs aptly puts it, lived experiences of women is a key place from which to build knowledge and foment social change' and that 'only by experience can anyone realize how deep, and dark, and foul is that pit of abominations' (cited in Hesse-Biber, 2011, 2). Echoing this thought, Fonow and Cook (2005) regard the desire on the part of feminist researchers to focus on women's lived experiences as a way to recover what had been omitted or distorted in academic knowledge about women and gender.

Growing Up Married is evidence for the idea that the voices of women and those oppressed need to be heard. The voice of one former bride plays a particularly important role in the film. Leyla is heard singing, something she hasn't done since she was 14 , since she was forced to marry her ex-husband. This highlights the restrictions that women who have been forced to be child brides have to face every day and the impact that marriage has on their sense of self. Leyla carries out a self-imposed singing ban to separate the horrors of her married life from better times in her childhood when she sang to express herself. This is why I chose to start and end the film with her singing voice. Indeed, Growing Up Married provides an avenue for disclosure and how critical it is for facilitating a positive outcome for the interviewees. Leyla used to keep her hair cut short to prevent her husband from hurting her as much when violently grabbing it for the purposes of sexual pleasure. The film ends with her words (a year after the filming took place) and photo, in which she has long hair: "Since last July [2015], since I talked to you, I stopped cutting my hair short and have been letting it grow!" It is through films, and the process of making films and talking to women, that we, as feminist academics, may have the 
power to contribute to change. There is a parallel to be made here in regard to the rationale behind the making of the film. It is crucial, in this context, to understand that women whose experiences are silenced, whose stories are marginalised, when they talk aloud, they become agents of change, directly for their own lives, and indirectly for others beyond the cultures they come from. It is also important to note that, after most public screening of the film to date, there was a disclosure from the members of the audience, telling me about their own experiences of forced marriage and other forms of violence, and at times, asking for where they can seek support.

Silence and invisibility, or voice and visibility are key here. Forced marriage and child marriage are alarming human rights issues. I chose to put a rolling number on the corner of the screen as the film runs. Every 27 minutes (the screening time of the film) 710 more girls become child brides somewhere in the world. These are recorded figures. At times, particularly in Turkey, there is no paperwork involved, the marriages are often illegally conducted at local mosques by local religious authorities; and, girls are not always given birth certificates so that families can 'sell' them into marriage as soon as they reach puberty, by faking their age. These crimes are unseen and their perpetrators go unpunished. Stories similar to the ones depicted in the film are everywhere in Turkey and beyond. But they are not as visible as they should be or they are not loud enough to be heard. Films in particular, and cultural products in general, represent aspects of reality. If we want to see a change in reality we need a change in the films and media that seek to represent it. This is why making films helps with making the issue visible and audible while allowing these stories to travel around the world.

\section{References}

Care, http://www.care.org/work/womens-empowerment/child-marriage (Last accessed on January, 30, 2018). 
De Shong, Halimah A.F., 'Feminist Reflexive Interviewing: Researching Violence Against Women in St Vincent and the Grenadines' Caribbean Review of Gender Studies, Issue 7, 2013, pp. 1-24.

Fonow, Mary Margaret and Cook, Judith A., 'Feminist Methodology: New Applications in the Academy and Public Policy,' Signs, Vol. 30, No. 4, 2005, pp. 2211-2236.

Glesne, Corinne, Becoming Qualitative Researchers: An Introduction (4 ${ }^{\text {th }}$ Edition), Boston MA: Pearson, 2010.

Harding, Sandra, 'Feminist Standpoints' in Hesse-Biber, Sharlene Nagy (ed), Handbook of Feminist Research, California: Sage, 2012, pp. 46-65.

Hesse-Biber, Sharlene Nagy (ed), Handbook of Feminist Research, California: Sage, 2012.

Hurriyet, http://www.hurriyet.com.tr/turkiyede-her-3-evlilikten-biri-cocuk-evliligi-40023586 (Last accessed on January, 30, 2018).

Hlavka, Heather R., Kruttschnitt, Candace and Carbone-López, Kristin C., 'Revictimizing the Victims?: Interviewing Women About Interpersonal Violence' Journal of Interpersonal Violence, Vol 22, Issue 7, 2007, pp. 894 - 920.

Juhasz, Alexandra, 'No Woman Is an Object: Realizing the Feminist Collaborative Video' Camera Obscura, Vol. 18, No.3, 2003, pp. 71-97.

Kaplan, E. Ann, Feminism and Film, Oxford and New York: Oxford University Press, 2000.

Maynard, Mary and Purvis, June (eds), Researching Women's Lives from a Feminist Perspective, Oxon and New York: Taylor and Francis, 1994 [reprinted 2002] Munro, Kim, 'Hybrid Practices and Voice Making in Contemporary Female Documentary Film,' in Boel Ulfsdotter and Anna Backman Rogers (eds.) Female Agency and Documentary Strategies: Sibjectivities, Identity and Activism, Edinburgh: Edinburgh University Press, 2018, pp. 70-84. Ova, Nalan, 'The Representation of "Child Brides" in the Turkish Press,' Selcuk Iletisim, No.8, Vol.2, 2014, pp. 238-262.

Petrarca, Diana M. and Hughes, Janette M., 'Mobilizing Knowledge Via Documentary Filmmaking Is the Academy Ready? McGill Journal of Education, Vol.49, No.3, 2014, pp. 561-582. 
Riach, Kathleen, 'Exploring Participant-Centred Reflexivity in the Research interview' Sociology, Vol. 43, No.2, 2009, pp. 356-370.

Ribbens, Jane, 'Interviewing - An “Unnatural Situation”?' Women's Studies International Forum, Vol.12, No.6, 1989, pp. 579-592.

United Nations Children's Fund, Ending Child Marriage: Progress and Prospects, UNICEF, New York, 2014.

Tang, Ning, 'Interviewer and Interviewee Relationships Between Women' Sociology, Volume 36, No.3, 2002, pp. 703-721.

Waldman, Diane and Walker, Janet (eds), Feminism and Documentary, Minneapolis and London: University of Minnesota Press, 1999.

\section{Short bio:}

Dr Eylem Atakav is Senior Lecturer in Film and Television Studies and Associate Dean for Internationalisation at the University of East Anglia where she teaches courses on women, Islam and media; and Middle Eastern media. She is the author of Women and Turkish Cinema: Gender Politics, Cultural Identity and Representation(2012) and editor of Directory of World Cinema: Turkey (Intellect, 2013). She is currently co-leading an Arts and Humanities Research Council-funded project entitles British [Muslim] Values. 